\title{
Studies on the Potential Ecological Risk and Homology Correlation of Heavy Metal in the Surface Soil
}

\author{
Haiyuan Qiu \\ Fujian Monitoring Center of Geological Environment, Fuzhou 350001, China \\ E-mail: qiuhaiyuan@hotmail.com
}

This research was financially supported by Xiamen science and technology project (Grant No. 3502Z20063007), and a grant from the Major Program for Fujian coastal economic zone ecological geochemistry of the Ministry of Land and Resources, China (Grant No. 1212010310307)

\begin{abstract}
The present paper was attempted to investigate the distribution, the potential ecological hazards and the homologous relativity of heavy metals in soil of Fujian agricultural protection area on the both side of 324 National Road in Xiang'an of Xiamen City. We analyzed the content of heavy metals in the surface of farming soil using ICP-MS and evaluated the potential ecological hazard of heavy metals in the soil of agricultural protection zone in Xiang'an and further investigated the relevance of heavy metals in the soil by the classical Lars Hakanson potential ecological risk index method. Results showed that the potential ecological risk levels (hazard index) of eight kinds of heavy metals in Xiang'an area were classified in the order $\mathrm{Cd}(94.4)>\mathrm{Hg}(54.3)>$ As (46.7) $>\mathrm{Pb}(10.5)>\mathrm{Cu}(4.3)>\mathrm{Ni}(3.1)>\mathrm{Cr}(2.3)>\mathrm{Zn}(1.9)$, and the global potential ecological risk index (HI) of heavy metal was 216.8. The comprehensive evaluation of potential ecological risk of agricultural safety belonged to the moderate level. The major pollutants in this area were $\mathrm{Cd}$ and $\mathrm{Pb}$, which attained the middle ecological hazard level. Through the correlation analysis of heavy metals, we found that the main external sources of pollution were the waste gas after the combustion of petrol and diesel, the excessive application of pesticides and so on. The internal source of pollution was the high background values of new cover soil.
\end{abstract}

Keywords: Soil, Heavy metal, Ecological risk, Correlation

\section{Introduction}

Heavy metal in agricultural soils, with easy cumulative effects, is one of potentially harmful contaminants that can not be degraded by microorganisms, and is easily cumulated and absorbed by crops and their products (Cui, 2004, PP. 366-370), and causes metabolic disorders and growth and development obstruction of crops or genetic variation of agricultural products, and threatens human health and safety directly through the food chain (Qiu, 2002, PP. 18-20; Liu, 2005, P. 15; Lars, 1980, PP. 975-1001). The previous researches showed that: Cd concentration of plants was $0.2-0.8 \mathrm{mg} / \mathrm{kg}$ in general, but it could attained $1200 \mathrm{mg} / \mathrm{kg}$ in fern leaves; rice and other crops were also susceptible to absorbing Cd from soil, and thus achieved a high level (Xia, 2002, PP. 272-275; Yang, 1991, PP. 381-388); The presence of mercury had a serious poisoning effects on ecology (Li, 2004, PP. 33-40); excessive arsenic level hampered the nutrient absorption and caused the stunting, languishing and dying of plants through replacing P of DNA in the phosphate group (Li, 2004, PP. 1-10); excessive copper level could inhibit the chlorophyll synthesis of plants, and then growth, and thus result in output reduction of agricultural products (Wang, 2000, PP. 146-148); the normal lead level in plants was $0.05-3 \mathrm{mg} / \mathrm{kg}$, and when plants exerted its super-accumulation of $\mathrm{Pb}$, its level could amount to several thousand $\mathrm{mg} / \mathrm{kg}$ (Davis, 1990); chromium content in plants was about $0.05-0.50 \mathrm{mg} / \mathrm{kg}$, and when it was excessive, whether trivalent or hexavalent, could impose toxic effects on plants, inhibit the growth of crops, and thus result in yield reduction in different levels (Shi, 2003, PP. 410-412; Nriagu, 1988, PP. 134-135; Adriano, 1992, PP. 19-190; Wang, 1993, PP. 91-100; Chatterjee, 2000, PP. 69-74); zinc content in plants was generally $10-100 \mathrm{mg} / \mathrm{kg}$, and when it was too high (> 50mg/kg), Zn toxicity usually occurred (Xie, 1997, PP. 27-38; Collins, 1981); nickel content in plants ranged from 0.1 to $10 \mathrm{mg} / \mathrm{kg}$, and whether nickel was an essential element for plants was not clear at present. However, when Ni level in the plant tissues attained more than $50 \mathrm{mg} / \mathrm{kg}$ in dry weight, excessive Ni would cause harm to plants, and mainly through inhibiting the transfer of iron to the above ground, result in acute iron deficiency and chlorosis (Wang, 1993, PP. 213-216).

Xiang'an agricultural protection area is located in the east of Xiamen City, and the important farmland protection area with the total surface area of $351.6 \mathrm{~km}^{2}$. However, with the development of economy and acceleration of the 
urbanization process, construction land increased gradually year by year, conflicts between people and land sharpened increasingly, and man-made factors have been increasingly prominent to affect the soil environment. In the early 1990s, agricultural production in Xiang'an agricultural protection area was once detected high level of heavy metals exceeding the standard, which seriously affected agricultural production, processing and export, and caused enormous economic losses. Therefore, follow-up investigation on heavy metals of the soil in the region was of great far-reaching significance. A further study on the heavy metals distribution in cropland soil of Xiang'an was undertaken in order to analyze their difference in space in the present paper. Potential ecological risk index of heavy metals in croplands of Xiang'an was evaluated using the classic method of potential ecological risk index established in 1980 by Swedish scholar Hakanson based on sedimentology principle, in original combination with biological toxicity and ecological risk, as well as research levels with both existing and potential risk assessment (Chen, 1989, PP. 16- 25; Chen, 1992, PP. 369- 376), and considering the toxicity differences among various heavy metals and sensitivity of the environment to the heavy metal pollution, potential impact of heavy metals on the environment was more accurately displayed (Ye, 2004, PP. 14- 17).

\section{Materials and methods}

\subsection{Sample collection}

Location was implemented on the 1:24000 topographic maps by geometric grid method, and distribution density was $500 \mathrm{~m} \times 500 \mathrm{~m}$. Field location was mainly based on topographic in order to search for the environment conducive to the development of soil characteristics and the major agricultural production areas to sample. GPS was applied in the field location to obtain precise positioning. A total of more than 50 soil samples were collected, and their basic physical and chemical properties were measured in situ (pH value, redox potential, etc.). Soil was sampled according to the correlated regulations and standards promulgated by the Ministry of Geology and Mineral Resources and the National Environmental Protection Administration (GB/T15618-1995), and sampling process was supervised by the quality control and assurance system. The specific process was as follows: $0-20 \mathrm{~cm}$ tillage layer was sampled in the surface soil, and surface grass layer and debris was removed. Using multi-point sampling method, soil quality in each point should be the same as far as possible, and after a mixture of various points, $1 \mathrm{~kg}$ soil or so was sampled by quarter method. Collected soil samples were placed in sealed plastic bags, and those for the analysis of organic content should be placed in clean glass bottles (should be full). After that, all samples were sent to the lab for analysis. At the same time, using portable GPS locator, sampling sites were located in situ. Using $\mathrm{pH}-$ redox potential meter from Vario $\mathrm{pH}$ series (WTW, Germany), $\mathrm{pH}$ value and redox potential of the sampled soils were measured in situ.

\subsection{Laboratory sample processing}

According to the books titled "Modern analytical methods of soil elements" and the relevant national standards (GB/T17136-1997, GB/T17135-1997), collected samples were pretreated in order to reach the requirements of laboratory analysis. "Full-decomposition" method was applied in the treatment of all samples. Samples were digested mainly using electric heating plate (VIP-4000). Moreover, for mercury is a highly volatile element, the large amount of it would be dissipated into the atmosphere using the conventional acid-soluble digestion method, which would affect the accuracy of the final observation, therefore, mercury and other elements should not be measured by digestion at the same time. Mercury could be digested using MARS 240/50 microwave digestion instrument (CEM, USA). Through the Agilent 7500 inductively coupled plasma mass spectrometry (ICP-MS), elements in the extracts, such as chromium, nickel, copper, zinc, cadmium and lead, were detected, and using SK-2003 atomic fluorescence spectrometer (AFS), mercury and arsenic levels were determined. All laboratory glassware was soaked in 1:4 nitric acids for 24 hours, and then was rinsed for application. Reagents for trace metal element analysis were superior grade pure or higher, and solutions were prepared using milli-pore ultrapure water.

\subsection{Data analysis and evaluation method}

Potential ecological risk index method advanced by Swedish scholar Hakanson, according to the characteristics of heavy metal and its environmental behavior, is an approach to evaluate the heavy metal contamination from the perspective of sedimentology. It not only considers heavy metal level in the soil, but also associates ecological and environmental effects with toxicology, and evaluates pollution using comparable and equivalent property index grading method. The potential ecological risk index related to individual pollution coefficient, heavy metal toxicity response coefficient and potential ecological risk individual coefficient, and its formula was as follows: 


$$
\begin{gathered}
R I=\Sigma E_{r}^{i} \\
E_{r}^{i}=T_{r}^{i} \times C_{r}^{i} \\
C_{r}^{i}=C_{\text {surface }}^{i} / C_{n}^{i}
\end{gathered}
$$

Where $E_{r}^{i}$ was potential ecological risk individual coefficient, $T_{r}^{i}$ was toxicity response coefficient of a certain kind of metal toxicity using standard heavy metal toxicity coefficient developed by Hakanson as reference, among which heavy metal toxicity level was classified in the order $\mathrm{Pb}=\mathrm{Cu}>\mathrm{Zn}$, and toxicity coefficient of $\mathrm{Pb}$, $\mathrm{Cu}$ and $\mathrm{Zn}$ was 5, 5 and 1 , respectively. Where $C_{r}^{i}$ was individual pollution coefficient, $C_{\text {surface }}^{i}$ was the practically observed value of heavy metals in surface soil, and $C_{n}^{i}$ was relative ratio, which came from background values of soil heavy metals in Xiang'an. Grading standard of heavy metal individual pollution coefficient referred to the literatures (Chen, 1989, PP. 16- 25; Chen, 1992, PP. 369- 376; Ye, 2004, PP. 14- 17; Su, 1994, PP. 436-442). Grading standard of heavy metal pollution ecological risk coefficient and index was listed in Table 1 in detail.

\section{Results and analysis}

\subsection{Heavy metal level analysis in the topsoil of Xiang'an agricultural protection area}

Through the analysis of soil heavy metals observations in Xiang'an agricultural protection area (Table 2), using the average trend method for fitting calculation, 8 heavy metal elements such as As, Cd and so on in 50 surface soil samples were evaluated and assayed. Results showed that soil types in farmland protection area were bounded by highway 324, therefore, there was significant difference in the distribution of heavy metal level between north and south in the topsoil soil of protection area; $\mathrm{Cd}, \mathrm{Cr}, \mathrm{Cu}, \mathrm{Pb}$ and $\mathrm{Zn}$ level were rather significantly high in the east and west, which could be mainly attributed to the fact that topsoil soil in the north of highway had a long history of planting crops, main pollution sources resulted from the high-does application of pesticides and fertilization in agricultural production activities, and thus a large number of nutrient and several heavy metal elements accumulated in the topsoil; Ca level of cropland soil in the south was excessive high, which could be mainly attributed to the fact that southern cropland was located in the new inning region, and main pollution sources resulted from the great deal of cover soil shipped with high background values; In addition, $\mathrm{As}, \mathrm{Cu}, \mathrm{Ni}$ and $\mathrm{Pb}$ in the new inning area showed a striped area with high level, and their basic distribution trend was in accordance with state road 324. Based on this, its main pollution sources mainly resulted from vehicle exhaust, tire, road dust and so on, which was basically consistent with the research results of Su (1994, PP. 436-442) and Fang (2000, PP. 49-52).

By contrast and comparison, compared to Gejiu in Yunnan (Guo, 2005, PP. 108-112), Changchun (Lan, 2003, PP. 4-6) in Jilin and Longyan (Liu, 1995, PP. 68-73) in Fujian, the observed heavy metal level was lower than Changchun, which might ascribed to the fact that Changchun was the old industrial bases of China; Gejiu was a famous mining city, and therefore, heavy metal level was all higher than Xiang'an excluding Hg; Compared to Longyan in the same province, $\mathrm{Zn}, \mathrm{Cr}$ and $\mathrm{Pb}$ level was slightly higher, and the other was all lower, which might be attributed to the fact that Xiang'an region was key cropland protection area of Xiamen, and its surrounding environment was well protected with no large pollution sources and pollution factories. Therefore, heavy metal induced by the agricultural production and atmospheric deposition tended to be the cardinal pollution sources of heavy metals. As seen from the difference between heavy metal level and relative ratio (Table 2), $\mathrm{Cd}, \mathrm{As}, \mathrm{Pb}$, and Zn level increased significantly, which illuminated the reliability of the results directly and favorably. It also indicated that freeway had brought enormous pressure on the surrounding environment and agriculture protection with the rapid development of urbanization in recent years.

As seen from Table 2, $E_{r}^{i}$ value obviously indicated that Cd level belonged to the strong ecological hazard level, $\mathrm{Hg}$ and As belonged to the middle level, $\mathrm{Pb}$ belonged to the tiny level, and other heavy metals basically belonged to be none of the ecological hazard. Analyzing the external sources, anthropogenic sources played a critical role in $\mathrm{Cd}$ of the soil, i.e. heavy application of pesticides and fertilizers among which the majority containing $\mathrm{Cd}$ was phosphate and domestic waste; Main sources of $\mathrm{Hg}$ and $\mathrm{As}$ were from atmospheric deposition, irrigation, as well as chemical fertilizers and pesticides. Taken together, human agricultural production activities 
have played an unavoidable role in promoting the cropland heavy metal pollution. In the whole region, it was still at a middle ecological hazard level, and it was urgent to pay great attention to the factors resulting in potential ecological risk to cropland soil, with further monitoring in order to avoid a grater hazard.

\subsection{Correlation analysis of heavy metals in Xiang'an agricultural protection area}

Heavy metals in agricultural soils came mainly from the basic human activities and parent materials; correlation existed among homologous heavy metals, and according to the correlation, whether the sources were same or not could be estimated (Hu, 2003, PP. 214-218). Correlation between heavy metal levels and soil properties in the region was affected by the element itself, and also closely associated with the environment and pollution source of the element. The correlation resulted from the interaction of a variety of elements in certain environmental conditions, and relationship between elements and soil properties and the impacts of the properties on the accumulation of a certain element was observed. If there was significant correlation among the elements, it suggested that the possibilities that they came from the same pollution source was great, and such source might resulted from the combined pollution imposed by human activities, or the nature (geochemical sources) (Galley, 1985, PP. 1-18; Zhang, 1999, PP. 253-260; Wang, 1997, PP. 10-14).

Through the correlation analysis of cropland soil heavy metals in Xiang'an agricultural protection area (Table 3-4), results showed that there was high homology correlation in $\mathrm{Mn}-\mathrm{Ni}, \mathrm{Cu}-\mathrm{As}, \mathrm{Cu}-\mathrm{Cd}$ and $\mathrm{Cd}-\mathrm{As}$, their pollution sources basically from the same place, and the pollution was the combined pollution caused by human agricultural activities. In addition, there was no high correlation among $\mathrm{Hg}$ or $\mathrm{Pb}$ and all other elements, which indicated that their pollution sources and accumulation had a certain particularity. Among them, there was high correlation among As and other considerable elements, which suggested that its main sources were from natural geochemistry. There was quite high correlation between $\mathrm{Cu}$ and $\mathrm{Cd}$, which showed that part sources were same, and mainly from the pesticides, fertilizers and plastic film. According to the source, heavy metal pollution derived from human agricultural production could be targeted to avoid.

Compared to the correlation among the elements in sediments along the coastline in the region (Liu, 1995, PP. 68-73; Hu, 2003, PP. 214-218; Galley, 1985, PP. 1-18; Zhang, 1999, PP. 253-260), correlation trends among cropland soil elements in Xiang'an were of certain differences, which suggested that the pollution sources were not comparable. There was good correlation between two kinds of metal in soil, such as $\mathrm{Mn}-\mathrm{Ni}, \mathrm{Cu}-\mathrm{As}, \mathrm{Cu}-\mathrm{Cd}$, $\mathrm{Cd}$-As and so on, while no basic significant difference among their correlation in sediments, which may be attributed to the presence, sedimentation and accumulation of heavy metals in the river sediments, namely that the river attenuated the correlation between the soil and heavy metals in sediments due to the interference with the municipal wastewater and agricultural fertilizer pollution (Lan, 2003, PP. 4-6; Liu, 1995, PP. 68-73; Hu, 2003, PP. 214-218; Galley, 1985, PP. 1-18; Zhang, 1999, PP. 253-260). As seen from the comparison between soil and sediments, correlation coefficient between $\mathrm{Hg}$ and other elements in soil was higher than that in sediments, which was attributed to river pollution induced by $\mathrm{Hg}$. The emission of exogenous $\mathrm{Hg}$ pollutant attenuated the correlation between $\mathrm{Hg}$ and other elements. Correlation between $\mathrm{Mn}$ and other elements in soil and sediments varied significantly. There was a significant positive correlation between $\mathrm{Mn}$ and $\mathrm{Ni}$ in cropland soil; while a significant negative correlation in river sediments. Such opposite result might be contributive to the difference of their configuration induced by the external environmental factors of sediments and soil (such as $\mathrm{pH}$ value, redox potential, etc.). Its underlying mechanism still might need further investigation. It could be indicated that relationship among elements in the environment was partly associated with their sources and external environmental conditions.

\subsection{Integrated evaluation of soil heavy metal pollution and its potential ecological hazards in Xiang'an}

Excessive heavy metals, through the absorption of the root system in cropland soil, brought significant toxic effects on the crops. Jinadasa had measured 29 kinds of vegetables sold in Sydney (Wang, 1997, PP. 10-14), and Wang, et al had assayed the vegetables in Shenyang city. Results showed that leafy vegetables had better capacity of accumulating heavy metals than rhizome vegetables and melon and fruit vegetables among the agricultural products (Zhou, 2002, PP. 476-480; Jiandasa, 1997, PP. 924-933; Wang, 1994, PP. 84-88). Leafy vegetables not only absorbed heavy metals by the roots, but also could heavily assimilate elements in the atmosphere by laminas, such as $\mathrm{Pb}, \mathrm{Hg}$ and $\mathrm{Zn}$, etc. Crops with large leaf area and coarse foliage had strong capacity of absorbing elements (Zhang, 1997, PP. 30-33). The large number of $\mathrm{Cr}$ element moved to the soil environment along with the application of organic fertilizer mainly composed of the manure of pork and chicken, and after the absorption and migration of crop root system, $\mathrm{Cr}$ level exceeded the standard in plants. Similar to $\mathrm{Cd}, \mathrm{Zn}$ was considered to be the active elements which were most vulnerable to be accumulated by crops in the soil and transferred to the above ground (Wang, 1994, PP. 84-88; Zhang, 1997, PP. 30-33; Kang, 2003 , PP. 
68-71). Cd caused more harm than good for plants, and had a strong poisoning effect even at a trace level (Kang, 2003, PP. 68-71). Accordingly, heavy metal pollution in soil was significantly correlated to its level in the crops.

Adriano (1986), and Alloway (1995, PP. 11-24) have pointed out that $\mathrm{Pb}, \mathrm{Cu}$ and $\mathrm{Zn}$ level were the ideal indices to evaluate the pollution of urban soils. Currently, among the evaluation of the impact of agricultural soils pollution substances on the environment, the potential ecological risk index method of Hakanson have been applied more extensively and intensively, and was also a classic evaluation method which had a great influence in the world. In the present paper, through the investigation and analysis of physical properties, $\mathrm{pH}$, and heavy metals content in the topsoil, in combination with Hakanson's classic method, potential ecological risk of heavy metal pollution in topsoil was evaluated and analyzed. Results showed that in the topsoil of Xiang'an agricultural protection area, $\mathrm{Cd}$ content attained the strong pollution level while $\mathrm{Hg}$ and As the middle level, and other elements had lower potential ecological risk coefficient. After comparison, the potential ecological risk levels (hazard index) of eight kinds of heavy metals in Xiang'an area were classified in the order $\mathrm{Cd}>\mathrm{Hg}>\mathrm{As}>\mathrm{Pb}>$ $\mathrm{Cu}>\mathrm{Ni}>\mathrm{Cr}>\mathrm{Zn}$. Its integrated potential ecological risk index of heavy metals was 216.8, belonged to the middle ecological risk, and attained the pollution level that more attention should be paid to.

\section{Conclusions}

1) There was significant difference in the heavy metal level in Xiang'an agricultural protection area between north and south, and from the north of the highway, $\mathrm{Cd}, \mathrm{Cr}, \mathrm{Cu}, \mathrm{Pb}$ and, $\mathrm{Zn}$ level were rather significantly high in the east and west in topsoil, which could be mainly attributed to the fact that topsoil soil in the north of highway had a long history of planting crops, and human agricultural activities were more intense. Therefore, the whole heavy metal level was quite high. Form the south of the highway, $\mathrm{Ca}$ level of cropland soil in the south was excessive high, and $\mathrm{As}, \mathrm{Cu}, \mathrm{Ni}$ and $\mathrm{Pb}$ showed a striped area with high level, which could be mainly attributed to the large amount of vehicle exhaust from state road 324 and the great deal of cover soil shipped with high background values. Compared to other cities in China, currently, heavy metal level in cropland soil of Xiang'an agricultural protection area was still relatively low, and heavy metal induced by the agricultural production and atmospheric deposition tended to be the cardinal pollution sources of heavy metals. Differences between heavy metal levels and relative ratio obviously suggested that $\mathrm{Cd}, \mathrm{As}, \mathrm{Pb}$ and $\mathrm{Zn}$ level increased significantly in recent years, and further indicated that impacts of human activities on the pollution was tremendous evident (Table $3-4)$.

2) Through the correlation analysis of cropland soil heavy metals in Xiang'an agricultural protection area, results showed correlation among $\mathrm{Mn}-\mathrm{Ni}, \mathrm{Cu}-\mathrm{As}, \mathrm{Cu}-\mathrm{Cd}$ and $\mathrm{Cd}-\mathrm{As}$ was high with high homology, among them, correlation between $\mathrm{Cu}$ and $\mathrm{Cd}$ was particularly high. Meanwhile, $\mathrm{Mn}-\mathrm{Cr}, \mathrm{Ni}-\mathrm{Cr}, \mathrm{Mn}-\mathrm{Cu}, \mathrm{Ni}-\mathrm{Cu}, \mathrm{As}-\mathrm{Cr}, \mathrm{As}-\mathrm{Mn}$, As-Zn, Cd-Cr, Cd -Zn also had a certain degree of homology; In addition, there was high correlation among As and other considerable elements while no high correlation among $\mathrm{Hg}$ or $\mathrm{Pb}$ and all other elements. Taken together, in the topsoil of the region, heavy metal pollution mainly included three sources. One is vehicle exhaust; another important source is the heavy metal induced by the human agricultural production activities; the third one is the secondary pollution to the covering area resulted from the great deal of cover soil shipped with high background values. According to the source, measures should be taken against heavy metal pollution derived from human agricultural production effectively and pertinently.

3) Through the potential ecological risk index method of Hakanson, ecological risk of heavy metal pollution level in topsoil was evaluated. Results showed that the potential ecological risk levels of eight kinds of heavy metals in Xiang'an area were classified in the order $\mathrm{Cd}>\mathrm{Hg}>\mathrm{As}>\mathrm{Pb}>\mathrm{Cu}>\mathrm{Ni}>\mathrm{Cr}>\mathrm{Zn}$; Cd content attained the strong pollution level while $\mathrm{Hg}$ and As the middle level, and other elements had lower potential ecological risk coefficient. Its integrated potential ecological risk index of heavy metals was 216.8 , belonged to the middle ecological risk. Monitoring and management should be strengthened to avoid the man-made factors to further cause agricultural soil heavy metal pollution.

\section{References}

Adriano, D.C. (1986). Trace element in the terrestrial environment. Heidelberg: Springer-Verlag.

Adriano, D.C. (1992). Biogeochemistry of Trace Metals. Lewis Publishing, 19-190.

Alloway, B. J. (1995). Heavy metal in soils. Blackie, Academic and Professional, London, 11-24.

Chatterjee, C. (2000). Phytotoxicity of cobalt, chromium and copper in cauliflower. Environmental Pollution, 109:69-74.

Chen, J.S. \& Liu, Y.J. (1989). Potential hazard of water metal: evaluation by the application of sedimentological method. Environmental Science, 9(1):16-25. 
Chen, J.S., \& Zhou, J.Y. (1992). Studies on the heavy metals in Chinese water environment. Beijing: Chinese environmental science press, 369-376.

Collins, J.G. (1981). Zinc in effect of heavy metal pollution on plants. Applied Science Publishers, London.

Cui, D.J., \& Zhang, Y.L. (2004). Current situation of soil contamination by heavy metals and research advances on the remediation techniques. Chinese Journal of Soil Science, 35(3):366-370.

Davis, B.E. (1990). Heavy metals in Soils. Blackie Glasgow and London press.

Fang, S.B., Pan. J.J., \& Chen, C.H. (2000). Dynamic monitoring of town extension by using TM and SPOT remotely sensed data. Journal of Nanjing Agricultural University, 23(3): 49-52.

Galley, F.A., \& Lloyd, O.L. (1985). Grass and surface soils as monitors of atmospheric metal pollution in central Scotland. Water, Air and Soil Pollution, 24(1):1-18.

Guo, P., Xie, Z.L., \& Li, J., et al. (2005). Specificity of heavy metal pollution and the ecological hazard in urban soils of Changchun city. Scientia Geographica Sinica, 25(1):108-112.

Hu, Z.Q., Qi, J.Z., \& Si, J.T. (2003). Contamination and assessment of heavy metals in fly ash reclaimed soil. Transactions of the Chinese Society of Agricultural Engineering, 19(2):214-218.

Jiandasa, K.B.P.N., Milham, P.J., \& Hawkins, C.A., et al. (1997). Heavy metals in the environment-survey of cadmium levels in vegetables and soils of Greater Sydney. Australia J Environ Qual, 26:924-933.

Kang, L.J., Zhang, M.X., \& Luan, G.Y. (2003).Study on the rules of Ni accumulative in rice plants under the pollution condition. Journal of Northeast Normal University (Natural Science Edition), 35(4):68-71.

Lan, T.S., Lin, J., \& Chen, J.A., et al. (2003). Study on the heavy metal contamination in roadside soil and the ecological hazard. Strait Journal of Preventive Medicine, 9(1):4-6.

Lars Hakanson L. (1980). An ecological risk index for aquatic pollution control, a sedimentlogical approach. Water Research, 14(8): 975-1001.

Li, T.Q., \& Yang, X.E. (2004). Transfer of arsenic from agricultural soil to food chain. Guangdong Trace Elements Science, 11(1):1-10.

Li, Y.H., Wang, W.Y., \& Yang, L.S. (2004). A review of Mercury in environmental biogeochemistry. Progress in Geography, 23(6): 33-40.

Liu, F. (2005). Hazards of heavy metals on crops and human. Hebei Agriculture, (1):15.

Liu, Y.Q. (1995). Study and application of background values of Fujian coastline soil. Marine Environmental Science, 14(2):68-73.

Nriagu, J.O., \& Pacyna, J.M. (1988). Quantitative assessment of worldwide contamination of air, water and soils by trace metals. Nature, 333,134-13.

Qiu, D., Wan, X.H., \& Wang, S.C. (2002). Investigation about the heavy metal pollution of soil in basic farmland conservation area on Nanjing suburb. The Administration and Technique of Environmental monitoring, 14(5):18-20.

Shi, L.W. (2003). Studies on the effects of chromium complexes. Journal of Hygiene Research, 32(4):410-412.

$\mathrm{Su}$, N.H. (1994). Environmental chemical characteristics of heavy metals in Cultivated land Soil of Fujian. Journal of Fujian Agriculture and Forestry University, 23, (4):436-442.

Wang, D., Li, F.M., \& Xiong, Z.T. (2000). Relationship between copper's toxicity and phytoaccumulation. Soil and Environmental Sciences, 9(2): 146-148.

Wang, L.F., \& Bai, J.G. (1994). Pollution investigation and control way research of vegetables in Shenyang. Agro-Environmental Protection, 13(2):84-88.

Wang, P.X. (1993). Correlation between soil and Ni in the plants. Agricultural environment protection, 12(5):213-216.

Wang, X., \& Wu, Y.Y. (1997). Behavior characteristics of heavy metal in soil-rice system. Chinese Journal of Ecology, 16(4):10-14.

Wang, Y. (1993). Soil environmental element chemistry. Beijing: Chinese Environmental science press, 91-100.

Xia, Y.S., Wang, G.R., \& Zhang, G.L. (2002). Research advances in influence factors of phytotoxicity of Cadmium in soil. Agrio-environmental Protection, 21(3):272-275. 
Xie, J.S., Liao, X.F., \& Ne, J.H. (1997). Transference and accumulation of Zn in water-soil-plant system. Agricultural ecological environment, 4:27-38.

Yang, J.R. (1991). Effects of $\mathrm{Cd}$ and $\mathrm{Cu}$ on the toxicity of plant cells and its element absorption characteristics. Journal of Environmental Science, 11(3):381-388.

Ye, Y.Y., Zhang, H.O., \& Tan, S.C. (2004). A study on the potential ecological risk of heavy metals in soils of Gejiu urban area. Tropical Geography, 24(1):14-17.

Zhou, J.L., \& Chen, T. B. (2002).Situation and prospect of research on heavy metal pollution in vegetables and soils for vegetable cultivation in urban areas of China. Journal of Hubei Agricultural College, 22(5):476-480.

Zhang, N.M. (1997). Research status and prospect of heavy metal pollution in soil-plant system. Progress in Environmental Science, 7(4):30-33.

Zhang, S.X., Yi, Y.L., \& Liu, X.Y. (1999). Study on correlation between some metal element contents in soils of Caohekou area, Liaoning province and their affecting factors. Acta Pedologica Sinica, 36(2):253- 260.

Table 1. Grading standard of $E_{r}^{i}$ and RI

\begin{tabular}{|c|c|c|}
\hline Pollution coefficient $E_{r}^{i}$ & Pollution index RI & $\begin{array}{c}\text { Pollution level (ecological } \\
\text { hazard) }\end{array}$ \\
\hline$\leq 40$ & $\leq 150$ & tiny \\
\hline $40 \sim 79$ & $150 \sim 299$ & middle \\
\hline $80 \sim 159$ & $300 \sim 600$ & strong \\
\hline $160 \sim 320$ & $>600$ & very strong \\
\hline$>320$ & - & serious \\
\hline
\end{tabular}

Table 2. Assessment of the potential ecological risk of soil heavy metal in Xiang 'an

\begin{tabular}{|c|c|c|c|c|c|}
\hline Elements & $\begin{array}{c}\text { Toxicity } \\
\text { coefficient }\end{array}$ & $\begin{array}{c}\text { Observed } \\
\text { value } \\
\mathrm{mg} / \mathrm{kg}\end{array}$ & $\begin{array}{c}\text { Relative ratio* } \\
\mathrm{mg} / \mathrm{kg}\end{array}$ & $E_{r}^{i}$ & Hazard level \\
\hline $\mathrm{Hg}$ & 40 & 0.11 & 0.081 & 54.3 & Middle \\
\hline $\mathrm{Cd}$ & 30 & 0.17 & 0.054 & 94.4 & Strong \\
\hline $\mathrm{As}$ & 10 & 27.1 & 5.78 & 46.7 & Middle \\
\hline $\mathrm{Cu}$ & 5 & 18.4 & 21.6 & 4.3 & None \\
\hline $\mathrm{Pb}$ & 5 & 73.3 & 34.9 & 10.5 & Tiny \\
\hline $\mathrm{Ni}$ & 3 & 9.61 & 13.5 & 3.1 & None \\
\hline $\mathrm{Cr}$ & 2 & 48.5 & 41.3 & 2.3 & None \\
\hline $\mathrm{Zn}$ & 1 & 153.8 & 82.7 & 1.9 & None \\
\hline $\mathrm{RI}$ & & & & 216.8 & Middle \\
\hline
\end{tabular}

Note: *relative ratio the background value of soil environment in Fujian coastal region (Davis, 1990). 
Table 3. Statistic values of heavy metal element contents in the soils (mg/kg)

\begin{tabular}{|c|c|c|c|c|c|c|c|c|c|}
\hline Statistic & $\mathrm{Cr}$ & $\mathrm{Mn}$ & $\mathrm{Ni}$ & $\mathrm{Cu}$ & $\mathrm{Zn}$ & $\mathrm{As}$ & $\mathrm{Cd}$ & $\mathrm{Hg}$ & $\mathrm{Pb}$ \\
\hline Average & 48.5039 & 316.9463 & 9.6057 & 18.3993 & 153.8 & 27.0919 & 0.1741 & 0.108 & 73.2583 \\
\hline Max & 134.4 & 616.68 & 15.696 & 46.032 & 229.08 & 86.052 & 0.3132 & 1.2612 & 111.504 \\
\hline Min & 6.2496 & 41.88 & 1.8696 & 4.5732 & 45.516 & 5.7828 & 0.024 & 0.0528 & 24.372 \\
\hline $\begin{array}{c}\text { Standard } \\
\text { deviation }\end{array}$ & 28.0013 & 128.8315 & 3.3790 & 8.6738 & 50.0332 & 18.0256 & 0.0680 & 0.2133 & 21.9551 \\
\hline
\end{tabular}

Table 4. Correlation coefficient among heavy metal concentrations in Xiang'an

\begin{tabular}{|r|r|r|r|r|r|r|r|r|r|}
\hline & $\mathrm{Cr}$ & $\mathrm{Mn}$ & $\mathrm{Ni}$ & $\mathrm{Cu}$ & $\mathrm{Zn}$ & $\mathrm{As}$ & $\mathrm{Cd}$ & $\mathrm{Hg}$ & $\mathrm{Pb}$ \\
\hline $\mathrm{Cr}$ & 1 & 0.4189 & 0.5908 & 0.3931 & -0.0562 & 0.4218 & 0.4295 & -0.0645 & -0.0952 \\
\hline $\mathrm{Mn}$ & & 1 & 0.7842 & 0.5939 & 0.0860 & 0.4084 & 0.3790 & -0.1430 & -0.0091 \\
\hline $\mathrm{Ni}$ & & & 1 & 0.5428 & -0.070 & 0.2899 & 0.2359 & -0.0719 & 0.0126 \\
\hline $\mathrm{Cu}$ & & & & 1 & 0.2782 & 0.7347 & 0.7685 & 0.0107 & 0.2160 \\
\hline $\mathrm{Zn}$ & & & & & 1 & 0.4115 & 0.4879 & -0.0369 & 0.2160 \\
\hline $\mathrm{As}$ & & & & & & 1 & 0.6815 & 0.0075 & -0.1441 \\
\hline $\mathrm{Cd}$ & & & & & & & 1 & -0.0278 & -0.0125 \\
\hline $\mathrm{Hg}$ & & & & & & & & & 0.0893 \\
\hline $\mathrm{Pb}$ & & & & & & & & & 1 \\
\hline
\end{tabular}

